\title{
Butein inhibits NF-кB, AP-1 and Akt activation in adult T-cell leukemia/lymphoma
}

\author{
CHIE ISHIKAWA $^{1,2}$, MASACHIKA SENBA ${ }^{3}$ and NAOKI MORI ${ }^{1}$ \\ ${ }^{1}$ Department of Microbiology and Oncology, Graduate School of Medicine, University of the Ryukyus, Nishihara, \\ Okinawa 903-0215; ${ }^{2}$ Division of Health Sciences, Transdisciplinary Research Organization for Subtropics \\ and Island Studies, University of the Ryukyus, Nishihara, Okinawa 903-0213; ${ }^{3}$ Department of Pathology, \\ Institute of Tropical Medicine, Nagasaki University, Nagasaki 852-8523, Japan
}

Received January 23, 2017; Accepted May 8, 2017

DOI: $10.3892 /$ ijo.2017.4026

\begin{abstract}
Human T-cell leukemia virus type 1 (HTLV-1) is the causative agent of adult T-cell leukemia/lymphoma (ATLL) but there is no effective treatment for HTLV-1-associated diseases. Herein, we determined the effect of butein, a bioactive plant polyphenol, on cell growth, apoptosis and signaling pathways in HTLV-1-infected T-cell lines and on tumor growth in SCID mice. Treatment with butein caused a decrease in viability of HTLV-1-infected T-cell lines. T cells cultured with butein showed obvious apoptosis morphology, and cleavage of poly(ADP-ribose) polymerase with activation of caspase-3, - 8 and -9 . Pretreatment of cells with caspase inhibitor partially blocked butein-induced inhibition of cell viability. Butein also resulted in cell cycle arrest at $\mathrm{G}_{1}$ phase. Butein markedly downregulated the protein expression levels of CDK4, CDK6, cyclin D1, cyclin D2, cyclin E, survivin, XIAP, c-IAP2 and phospho-pRb. Butein also inhibited i) total and phosphoprotein levels of I $\mathrm{B}$ kinase (IKK) $\alpha$ and IKK $\beta$, ii) degradation and phosphorylation of I $\mathrm{B} \alpha$, iii) JunB and JunD, iv) total and phospho-protein levels of Akt, v) phosphorylation of RelA, vi) heat shock protein 90, and vii) DNA-binding activity of $\mathrm{NF}-\kappa \mathrm{B}$ and AP-1. In mice harboring ATLL xenograft tumors, butein caused a significant inhibition of tumor growth and reduced serum levels of soluble interleukin- 2 receptor $\alpha$ chain and soluble cluster of differentiation 30. Considered together, the results indicated that butein has antiproliferative and proapoptotic properties through the suppression of $\mathrm{NF}-\kappa \mathrm{B}$, AP-1 and Akt signaling in HTLV-1-infected T cells, both in vitro and in vivo, suggesting its therapeutic potential against HTLV-1-associated diseases including ATLL.
\end{abstract}

Correspondence to: Professor Naoki Mori, Department of Microbiology and Oncology, Graduate School of Medicine, University of the Ryukyus, 207 Uehara, Nishihara, Okinawa 903-0215, Japan E-mail: naokimori50@gmail.com

Key words: butein, adult T-cell leukemia/lymphoma, human T-cell leukemia virus type 1 , nuclear factor- $\kappa \mathrm{B}$, activator protein-1, Akt, heat shock protein 90

\section{Introduction}

The retrovirus, human T-cell leukemia virus type 1 (HTLV-1), is associated with adult T-cell leukemia/lymphoma (ATLL) and chronic inflammatory disorders such as HTLV-1-associated myelopathy/tropical spastic paraparesis (HAM/TSP), uveitis and arthritis (1). Globally, approximately 20 million people are estimated to be infected by HTLV-1, and $90 \%$ of them remain asymptomatic carriers during their lives (2). ATLL is a highly aggressive malignancy of mature $\mathrm{CD} 4^{+} \mathrm{T}$ cells and develops only after a long period of latency, usually several decades (1). Despite advances in the development of novel therapeutic agents, the prognosis of ATLL remains poor, and there is no definite cure for HAM/TSP (1). Many patients acquire resistance to chemotherapeutic agents, leading to treatment failures. A higher viral load in individuals with HTLV-1 infection increases their risk of developing ATLL and HAM/ TSP $(3,4)$. Therefore, reduction of the number of HTLV-1infected $\mathrm{T}$ cells is crucial in the prevention and treatment of HTLV-1-associated diseases.

HTLV-1 induces oncogenesis through deregulation of selected cellular signaling pathways. In the virally infected $\mathrm{T}$ cells, activation of nuclear factor $-\kappa \mathrm{B}(\mathrm{NF}-\kappa \mathrm{B})$, activator protein-1 (AP-1) and Akt results in upregulation of expression of a large number of cellular genes involved in cell proliferation, survival and metastasis $(5,6)$. Thus, any new therapeutic agent must be designed to target multiple signal transduction pathways for maximum therapeutic benefits.

Natural phytochemicals, present in the human diet with cancer preventive and anticancer properties, are suitable alternatives (7). The plant polyphenol, butein (3,4,2',4'-tetrahydroxychalone), has been traditionally used as an oriental medicine in Eastern Asia, and has various biological functions $(8,9)$. Butein affects apoptosis, cell proliferation and the cell cycle in diverse cancers $(8,9)$. The preliminary results of a clinical trial on the effects of butein-containing flavonoids in gastric cancer patients showed it was safe with good tolerability, and produced marked decrease in tumor size (10). Thus, butein seems to be a potent anticancer agent. Several previous reports have suggested the involvement of $\mathrm{NF}-\kappa \mathrm{B}$, Akt, extracellular signal-regulated kinase, p38 kinase and p53 in the induction of cell cycle arrest at $G_{1}$ or $G_{2} / M$ and 
apoptosis, and inhibition of metastasis by butein in various cell lines $(8,9,11-13)$. Therefore, we hypothesized that butein may act as a chemopreventive and/or chemotherapeutic agent against HTLV-1-associated diseases.

We report herein that butein inhibits cell growth and stimulates apoptosis of HTLV-1-infected T cells by inhibiting NF- $\kappa \mathrm{B}, \mathrm{AP}-1$ and Akt activities and signaling pathways. Importantly, in a xenograft model, butein inhibited HTLV-1infected $\mathrm{T}$ cell-induced tumor growth. Our study revealed for the first time, butein effect on HTLV-1-infected T cells both in vitro and in vivo, and the molecular mechanism by which butein exhibited anti-ATLL effects.

\section{Materials and methods}

Reagents used. Butein (cat. no. B3803) was purchased from Tokyo Chemical Industry Co. (Tokyo, Japan), dissolved in dimethyl sulfoxide (DMSO) and used for the treatment of cells. The broad spectrum caspase inhibitor, Z-VAD-FMK (cat. no. G7232), was purchased from Promega Corp. (Madison, WI, USA). Antibodies against survivin (cat. no. 2808), Akt (cat. no. 9272), IкB kinase (IKK) $\alpha$ (cat. no. 2682), IKK $\beta$ (cat. no. 2684), phospho-Akt (Thr308) (cat. no. 13038), phospho-Akt (Ser473) (cat. no. 4060), phospho-IкB $\alpha$ (Ser32 and 36) (cat. no. 9246), phospho-IKK $\alpha / \beta$ (Ser176/180 and Ser177/181) (cat. no. 2694), RelA (cat. no. 8242), phospho-RelA (Ser536) (cat. no. 3033), cleaved caspase-3 (cat. no. 9664), -8 (cat. no. 9496), -9 (cat. no. 9501) and poly(ADP-ribose) polymerase (PARP) (cat. no. 9541) were purchased from Cell Signaling Technology, Inc. (Beverly, MA, USA). Antibodies against Bcl-2 (cat. no. MS-597), CDK2 (cat. no. MS-617), CDK4 (cat. no. MS-299), CDK6 (cat. no. MS-398), cyclin E (cat. no. MS-870), retinoblastoma protein (pRb) (cat. no. MS-107) and actin (cat. no. MS-1295) were obtained from Neomarkers, Inc. (Fremont, CA, USA). Antibodies against XIAP (cat. no. M044-3), cyclin D1 (cat. no. K0062-3), heat shock protein (HSP)70 (cat. no. SR-812C), phospho-pRb (Ser780) (cat. no. M054-3S) were purchased from Medical \& Biological Laboratories, Co. (Aichi, Japan). Antibodies against cyclin D2 (cat. no. sc-593), c-IAP2 (cat. no. sc-7944), ІкB $\alpha$ (cat.no.sc-371),JunB (cat.no. sc-46) and JunD (cat.no. sc-74), and NF- $\kappa B$ subunits p50 (cat. no. sc-114X), p52 (cat. no. sc-298X), RelA (cat. no. sc-109X), c-Rel (cat. no. sc-70X) and RelB (cat. no. sc-226X), and AP-1 subunits c-Fos (cat. no. sc-52X), FosB (cat. no. sc-48X), Fra-1 (cat. no. sc-605X), Fra-2 (cat. no. sc-604X), c-Jun (cat.no. sc-45X), JunB (cat.no. sc-46X) and JunD (cat. no. sc-74X) for supershift assay were from Santa Cruz Biotechnology, Inc. (Santa Cruz, CA, USA). Antibody against HSP90 (cat. no. 610418) was from BD BioSciences (San Jose, CA, USA).

Cell culture. The HTLV-1-infected MT-4 and HUT-102, and ATLL-derived TL-OmI T-cell lines, were cultured in RPMI-1640 medium (cat. no. 30264-56, Nacalai Tesque, Inc., Kyoto, Japan) supplemented with $10 \%$ heat-inactivated fetal bovine serum (Biological Industries, Kibbutz Beit Haemek, Israel) and 1\% penicillin/streptomycin (cat. no. 09367-34, Nacalai Tesque, Inc.). Cells were maintained in a $37^{\circ} \mathrm{C}, 5 \%$ $\mathrm{CO}_{2}$ humidified incubator. The study also included peripheral blood mononuclear cells (PBMCs) obtained from a healthy donor. PBMC proliferation was induced with $20 \mu \mathrm{g} / \mathrm{ml}$ of phytohemagglutinin (PHA) (cat. no. L8754, Sigma-Aldrich Co., St. Louis, MO, USA).

Cell proliferation and cytotoxic assay. The cell proliferative and toxic effects of butein were determined by the watersoluble tetrazolium (WST)-8 uptake method. Cells were plated $\left(1 \times 10^{4}\right.$ cells per well) in 96-well microtiter plates in triplicate and treated with various concentrations of butein. After incubation for 24-72 h, $10 \mu \mathrm{l}$ of the WST-8 reagent (cat. no. 07553-44, Nacalai Tesque, Inc.) was added to each well. After $4 \mathrm{~h}$, WST-8 reduction was measured at $450 \mathrm{~nm}$ using a $680 \mathrm{XR}$ microplate reader (Bio-Rad Laboratories, Inc., Hercules, CA, USA). Values were normalized to untreated control samples. The 50\% growth inhibitory concentration $\left(\mathrm{IC}_{50}\right)$ value was calculated by dotting the data points to a logistic curve using the CalcuSym software (version 2.0; Biosoft, Cambridge, UK).

Analysis of cell apoptosis. Cells were treated with vehicle or butein for 24-72 $\mathrm{h}$ and then permeabilized by incubation on ice for $20 \mathrm{~min}$ with $100 \mu \mathrm{g} / \mathrm{ml}$ of digitonin, and treated with phycoerythrin-conjugated APO2.7 antibody (cat. no. IM2088, Beckman Coulter, Inc., Marseille, France) for $15 \mathrm{~min}$ at room temperature. After staining with APO2.7 antibody, apoptosis was determined by Epics XL flow cytometry (Beckman Coulter, Inc., Brea, CA, USA). In addition, for analysis of morphological changes in nuclei, cells were stained by $10 \mu \mathrm{g} / \mathrm{ml}$ of Hoechst 33342 (cat. no. 346-07951, Dojindo Molecular Technologies, Inc., Kumamoto, Japan) and observed under a Leica DMI6000 microscope (Leica Microsystems, Wetzlar, Germany).

In vitro measurement of caspase Activity. Caspase activity was measured using Colorimetric Caspase Assay kits (cat. nos. 4800, 4805 and 4810, Medical \& Biological Laboratories, Co.). Briefly, cell extracts were recovered using the cell lysis buffer supplied with the kit and assessed for caspase-3, -8 and -9 activities using colorimetric probes. The assay kits are based on detection of chromophore $\varrho$-nitroanilide after cleavage from caspase-specific labeled substrates. Colorimetric readings were performed in an automated microplate reader.

Cell cycle analysis. Cells were stained with the CycleTEST Plus DNA Reagent kit (cat. no. 340242, Becton-Dickinson Immunocytometry Systems, San Jose, CA, USA). The cell cycle distribution was analyzed for 10,000 collected cells by an Epics XL flow cytometry that uses the MultiCycle software (version 3.0; Phoenix Flow Systems, San Diego, CA, USA). The population of nuclei at each phase of the cell cycle was determined and apoptotic cells with hypodiploid DNA content were detected in the sub- $\mathrm{G}_{0} / \mathrm{G}_{1}$ region.

Western blot analysis. Whole cell extracts were prepared by subjecting butein-treated cells to lysis in lysis buffer [ $62.5 \mathrm{mM}$ Tris-HCl (pH 6.8) (cat. no. 35434-21, Nacalai Tesque, Inc.), $2 \%$ sodium dodecyl sulfate (cat. no. 31607-65, Nacalai Tesque, Inc.), $10 \%$ glycerol (cat. no. 17045-65, Nacalai Tesque, Inc.), 6\% 2-mercaptoethanol (cat. no. 21438-82, Nacalai Tesque, Inc.) and $0.01 \%$ bromophenol blue (cat. no. 021-02911, Wako 

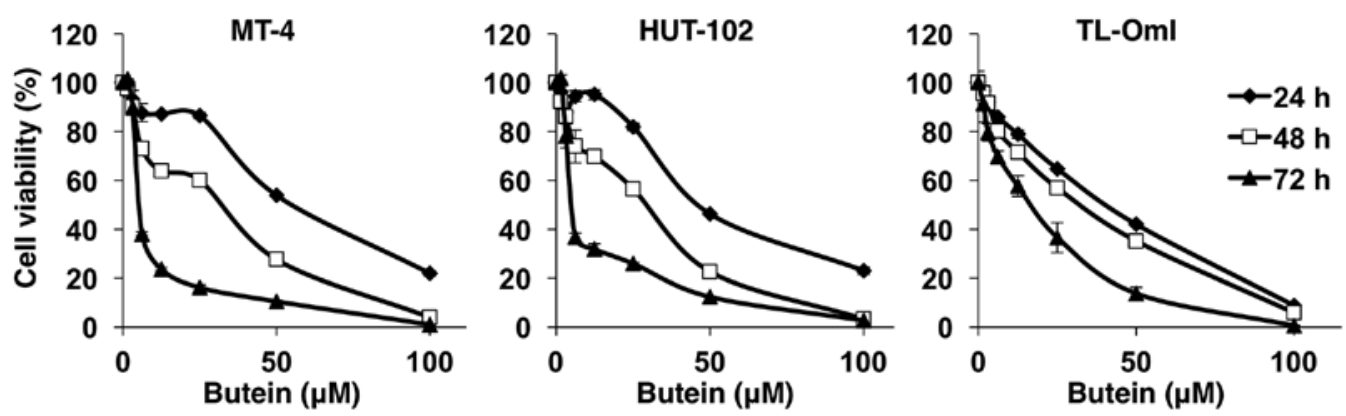

Figure 1. Effect of butein on cell viability. The indicated HTLV-1-infected T-cell lines were treated with butein (1.56-100 $\mu \mathrm{M})$ for 24-72 h, and the viability of cells was determined by the WST- 8 assay. Data are mean \pm SD of triplicate cultures and represent the percentage of cell viability.

Pure Chemical Industries, Osaka, Japan)]. Lysates were spun to remove insoluble material. The supernatants were collected and kept at $-80^{\circ} \mathrm{C}$. Protein concentrations were determined using a commercial kit (DC Protein Assay, cat. no. 5000116JA, Bio-Rad Laboratories, Inc.). Equal amounts of protein extracts $(20 \mu \mathrm{g})$ were resolved on sodium dodecyl sulfatepolyacrylamide gels (SDS-PAGE). After electrophoresis, the proteins were electrotransferred onto polyvinylidene difluoride membranes (cat. no. IPVH00010EMD, Millipore, Darmstadt, Germany), blotted with the relevant antibodies. Finally, blots were hybridized with horseradish peroxidaseconjugated secondary anti-mouse (cat. no. 7076, Cell Signaling Technology, Inc.) or anti-rabbit IgG antibody (cat. no. 7074, Cell Signaling Technology, Inc.) and developed using an enhanced chemiluminescence reagent (cat. no. RPN2232, Amersham Biosciences Corp., Piscataway, NJ, USA).

$R T$-PCR. TRIzol reagent (cat. no. 15596026, Invitrogen Life Technologies, Carlsbad, CA, USA) was used to extract total RNA from cells. RNA $(1 \mu \mathrm{g})$ was reverse transcribed into cDNA using a PrimeScript RT-PCR kit (cat. no. RR014A, Takara Bio Inc., Otsu, Japan). The sequence-specific primers used for RT-PCR were as follows: for $\mathrm{I} \kappa \mathrm{B} \alpha$, forward 5'-GCCTGGACTCCATGAAAGAC-3', reverse 5'-CAAGTG GAGTGGAGTCTGCTGCAGGTTGTT-3'; and for GAPDH, forward 5'-GCCAAGGTCATCCATGACAACTTTGG-3', reverse 5'-GCCTGCTTCACCACCTTCTTGATGTC-3'. PCR amplifications were performed in a programmable thermal cycler. Results were analyzed at 30 cycles to obtain results at exponential levels of amplification.

Electrophoretic mobility shift assay (EMSA). To determine $\mathrm{NF}-\kappa \mathrm{B}$ and AP-1 activation, we prepared nuclear extracts from butein-treated cells and performed EMSA, as previously described (14). Nuclear extracts were incubated with ${ }^{32} \mathrm{P}$-labeled probes. The top strand sequences of the oligonucleotide probes or competitors were as follows: for a typical NF- $\kappa \mathrm{B}$ element of the interleukin-2 receptor $\alpha$ chain $(I L-2 R \alpha)$ gene, 5'-GATCC GGCAGGGGAATCTCCCTCTC-3' and for the consensus AP-1 element of the $I L-8$ gene, 5'-GATCGTGATGACTCA GGTT-3'. The above underlined sequences are the NF- $\kappa$ B and AP-1 binding sites, respectively. In competition experiments, nuclear extracts were preincubated for $15 \mathrm{~min}$ with 100 -fold excess of unlabeled oligonucleotides. For supershift assays, nuclear extracts were incubated with antibodies against $\mathrm{NF}-\kappa \mathrm{B}$ or AP-1 subunits for $45 \mathrm{~min}$ at room temperature before the complex was analyzed by EMSA. The dried gels were visualized.

Xenograft tumor model.Five-week-old female C.B-17/Icr-severe combined immune deficient (SCID) mice were obtained from Kyudo, Co. (Tosu, Japan). To induce malignancy, 1x107 HUT-102 cells suspended in sterile RPMI-1640 medium (200 $\mu \mathrm{l})$ were inoculated subcutaneously into the postauricular region of SCID mice. The mice were divided at random into two treatment groups $(n=6$, each). Butein was solubilized in soybean oil (cat. no. 190-03776, Wako Pure Chemical Industries) and administered at a dose of $0.7 \mathrm{mg} / \mathrm{kg}$ intraperitoneally three times a week, and the treatment was continued for 27 days, beginning on the day after cell inoculation. The control group received the vehicle only. The tumor diameter was measured weekly with a shifting caliper and tumor volume was calculated. The mice were also weighed weekly, beginning on day 0 . All mice were sacrificed on day 28. The tumors were excised and their weight measured. At the end of the study, blood samples were collected and the sera were separated by centrifuging blood and then stored at $-80^{\circ} \mathrm{C}$ until assayed for secreted soluble IL-2R $\alpha$ [soluble cluster of differentiation 25 (sCD25)] and SCD30. This experiment was performed according to the Guidelines for Animal Experimentation of the University of the Ryukyus (Nishihara, Japan), and was approved by the Animal Care and Use Committee of the University of the Ryukyus (reference no. 5837).

Morphological analysis of tumor tissues and terminal deoxynucleotidyl transferase deoxyuridine triphosphate nick end labeling (TUNEL) assay. The tumor specimens were collected from the control mice group and $0.7 \mathrm{mg} / \mathrm{kg}$ butein group, fixed in formalin (Wako Pure Chemical Industries) solution, dehydrated through graded ethanol series (Japan Alcohol Selling Co., Tokyo, Japan) and embedded in paraffin (cat. no. 09620, Sakura Finetek Japan Co., Tokyo, Japan). The paraffinembedded specimens of ATLL tumors were stained with hematoxylin and eosin (H\&E, cat. nos. 234-12 and 1159350025, Merck, Darmstadt, Germany) and examined histologically. Analysis of DNA fragmentation by TUNEL testing was performed using a commercial kit (cat. no. 11684817910, Roche Applied Science, Penzberg, Germany). Cells were examined under a light microscope (Axioskop 2 Plus) with an Achroplan 40x/0.65 lens (both from Zeiss, Hallbergmoos, Germany). Images were acquired with an AxioCam 503 color and AxioVision LE64 software (Zeiss). 
A
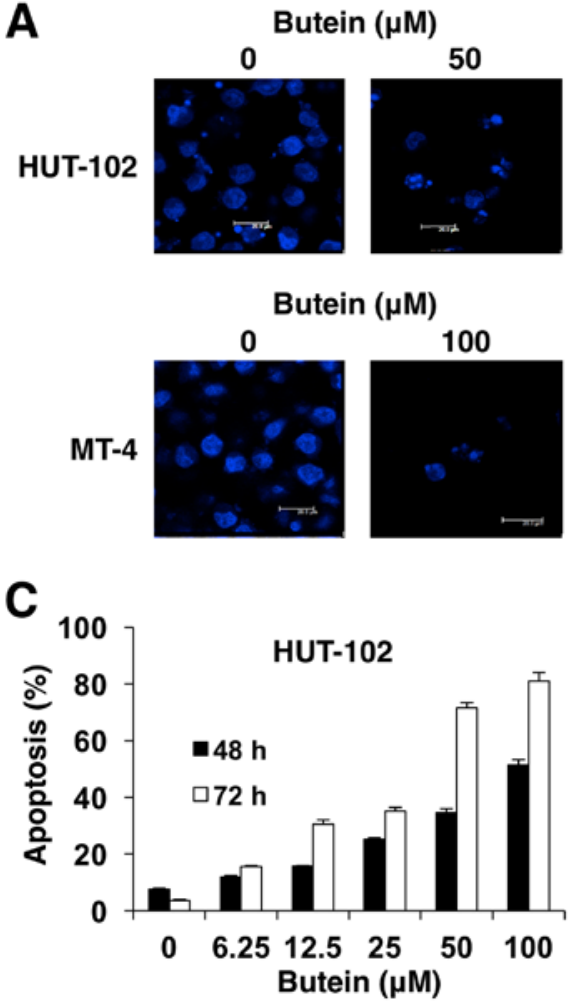

B
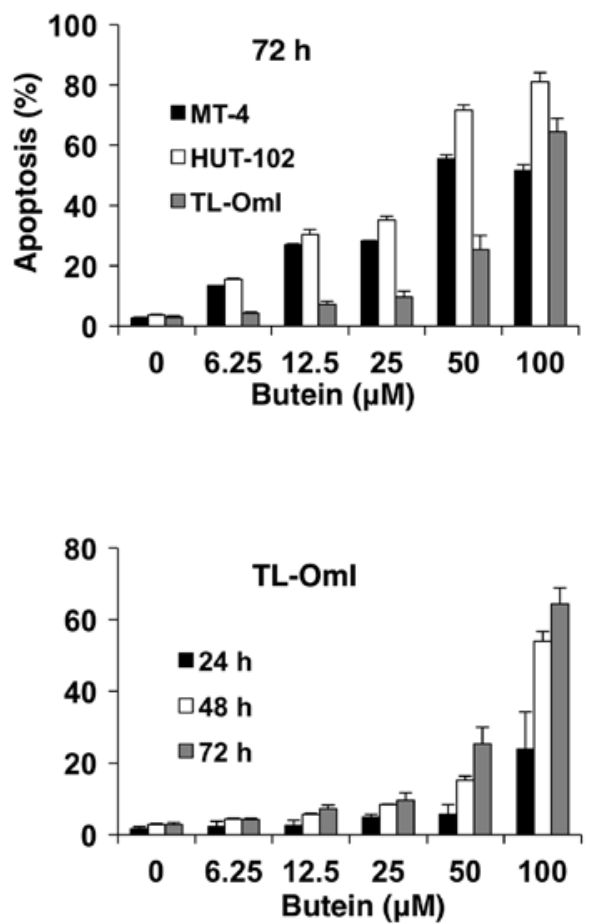

Figure 2. Butein induces apoptosis in vitro. (A) Fluorescence micrograph of cells stained with Hoechst 33342. HUT-102 and MT-4 cells were treated with 50 and $100 \mu \mathrm{M}$ of butein, respectively, for $48 \mathrm{~h}$, and analyzed by microscopy after Hoechst 33342 staining. (B and C) Quantitative analysis of cell apoptosis by APO2.7 staining flow cytometry. HTLV-1-infected T-cell lines were treated with different concentrations of butein $(6.25-100 \mu \mathrm{M})$ for the indicated time periods and analyzed by flow cytometry after APO2.7 staining. Data are mean \pm SD values of triplicate cultures.

Biomarker analysis. Serum concentrations of human SCD25 (cat. no. DR2A00, R\&D Systems, Inc., Minneapolis, MN, USA) and human sCD30 (cat. no. SK00582-01, Aviscera Bioscience, Inc., Santa Clara, CA, USA) were measured by enzyme-linked immunosorbent assay (ELISA), according to the protocol supplied by the manufacturer.

Statistical analysis. Values are shown as mean \pm standard deviation (SD). Data of two groups were compared by the Student's $\mathrm{t}$-test. Differences were considered significant at $\mathrm{P}<0.05$.

\section{Results}

Effects of butein on cell proliferation and cytotoxicity of $H T L V$-1-infected T-cell lines. To determine the in vitro effects of butein in ATLL cells, two HTLV-1-infected T-cell lines (MT-4 and HUT-102) and an ATLL-derived T-cell line (TL-OmI) were cultured in the presence of butein (1.56-100 $\mu \mathrm{M})$. As shown in Fig. 1, 24-72 h culture with butein significantly reduced cell proliferation and viability in a concentration- and time-dependent manner, with $\mathrm{IC}_{50}$ values at $72 \mathrm{~h}$ of $7.0 \mu \mathrm{M}$ for HUT-102, 7.9 $\mu \mathrm{M}$ for MT- 4 and $9.8 \mu \mathrm{M}$ for TL-OmI. In contrast, the $\mathrm{IC}_{50}$ was $27.8 \mu \mathrm{M}$ for normal PBMCs. Butein suppressed the proliferative response of PBMCs to the T cell mitogen PHA, with $\mathrm{IC}_{50}$ of $18.5 \mu \mathrm{M}$. Although the $\mathrm{IC}_{50}$ values for HTLV-1-infected T-cell lines were lower than those for normal PBMCs, obvious selective cytotoxic activities of butein on HTLV-1-infected T-cell lines have not been demonstrated.
Butein simultaneously induces cell apoptosis and cell cycle arrest. First, the effect of butein on cell morphology was examined using microscopy. Cells cultured with butein for $48 \mathrm{~h}$ demonstrated morphologies characteristic of apoptosis, such as chromatin condensation and nuclear fragmentation (Fig. 2A). To further investigate the mode of butein-induced cell death, HTLV-1-infected T-cell lines were treated with 6.3-25 $\mu \mathrm{M}$ butein for $24 \mathrm{~h}$. Butein induced concentration-dependent increases in the sub- $\mathrm{G}_{0} / \mathrm{G}_{1}$ population (Fig. $3 A$ and B). We also assessed the expression of $38-\mathrm{kDa}$ mitochondrial membrane antigen APO2.7 during apoptosis (15). Apoptotic cells (APO2.7-positive) increased after treatment with butein concentration- and time-dependently (Fig. 2B and C). Collectively, these results indicate that butein induces apoptosis of HTLV-1-infected T-cell lines. In addition to apoptosis, the same experiment also showed that butein dose-dependently increased the percentage of cells in the $G_{0} / G_{1}$ phase and also reduced the percentage of cells in the S phase (Fig. 3A and B). Considered together, the results showed the arrest of more cells at the $\mathrm{G}_{0} / \mathrm{G}_{1}$ phase of the cell cycle.

Butein induces caspase activation. The apoptotic process is executed by a member of the highly conserved cysteine proteases, caspases. Initiator caspase- 8 and -9 or effector caspase- 3 are synthesized as inactive proenzymes and become finally activated by proteolytic cleavage (16). To identify the mechanism underlying butein-induced apoptosis of HTLV-1infected $\mathrm{T}$ cells, we investigated cleavage of caspase- $3,-8$ and -9 , and also PARP, a substrate for caspase-3. Exposure 
A
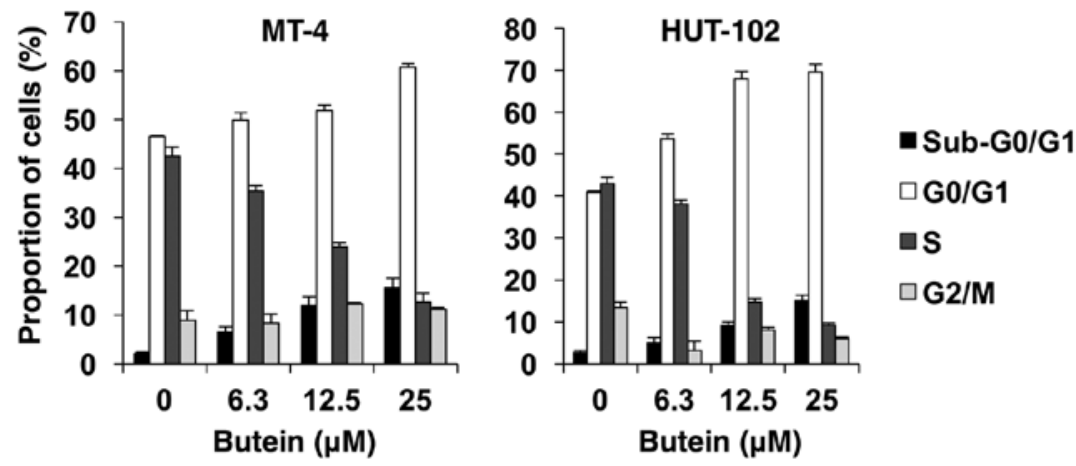

B

MT-4
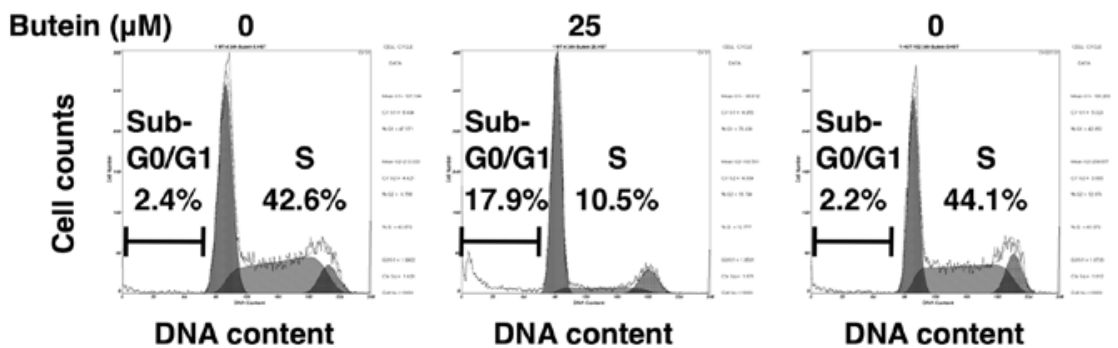

HUT-102

Figure 3. Cell cycle analysis. (A) MT-4 and HUT-102 cells were treated with different concentrations of butein (6.3-25 $\mu$ M) for $24 \mathrm{~h}$, and flow cytometry was used to detect the cell cycle phase distribution and cell death in the sub- $\mathrm{G}_{0} / \mathrm{G}_{1}$ phase. The percentage of each cell cycle fraction was quantified by MultiCycle software. Data are mean \pm SD values of triplicate cultures. (B) Representative results of an experiment conducted in triplicate with similar results.

of MT-4 and HUT-102 cells to butein (12.5-100 $\mu \mathrm{M}$ for $48 \mathrm{~h})$ caused concentration-dependent increase in the cleavage of caspase-3, -8 and -9, and PARP (Fig. 4A), as well as increase in activities of caspase-3, -8 and -9 (Fig. 4B). To further explore the significance of the latter activation, a broad spectrum caspase inhibitor, Z-VAD-FMK, was used to suppress the effect of butein. Pretreatment of cells with Z-VAD-FMK partially attenuated butein-induced inhibition of cell viability (Fig. 4C), suggesting that butein-mediated cytotoxic effect is mediated, at least in part, through a caspase-dependent apoptosis pathway.

Effects of butein on regulatory proteins involved in cell cycle regulation and apoptosis. Cell cycle progression is tightly regulated by interaction between CDKs and cyclins (17). To identify the molecular mechanism underlying butein-induced $\mathrm{G}_{0} / \mathrm{G}_{1}$ arrest, cells were cultured with butein (12.5-100 $\left.\mu \mathrm{M}\right)$ for $48 \mathrm{~h}$. They were harvested for protein extraction and western blot analysis. As shown in Fig. 5A, levels of CDK4, CDK6, cyclin D2 and cyclin E proteins were significantly decreased in butein-treated MT-4 and HUT-102 cells, compared to DMSO-treated cells. Butein also inhibited the expression of cyclin D1 in HUT-102 but not in MT-4 cells. However, butein had no significant effect on CDK2 protein level. Furthermore, butein induced dephosphorylation of $\mathrm{pRb}$ protein (Fig. 5A, top panels) and changed the hyperphosphorylated form to a hypophosphorylated form of pRB (Fig. 5A, second panels). The deregulation of apoptosis is often studied by the expression of anti-apoptotic proteins. There was a dose-dependent decrease in the protein expression of survivin and XIAP, but not Bcl-2, in butein-treated MT-4 and HUT-102 cells. Butein also inhibited the expression of c-IAP2 in HUT-102 but not in MT-4 cells (Fig. 5B). The effects of butein seem to slightly differ dependent on cell lines.

Butein inhibits $N F-\kappa B$ in HTLV-1-infected T-cell lines. $\mathrm{NF}-\kappa \mathrm{B}$ forms a family of transcription factors that regulate numerous biological processes, including immune response, inflammation, cell growth, survival and development. The $\mathrm{NF}-\kappa \mathrm{B}$ proteins are usually sequestered in the cytoplasm by a family of inhibitors, including I $\mathrm{I} B \alpha$. I $\kappa \mathrm{B} \alpha$ degradation is mediated through its phosphorylation by IKK, a trimeric complex composed of two catalytic subunits, IKK $\alpha$ and IKK $\beta$, and a regulatory subunit, IKK $\gamma$ (18). Incubation of MT-4 and HUT-102 cells with butein resulted in significant dosedependent inhibition of phosphorylation and upregulation of I $\mathrm{B} \alpha$ protein (Fig. 6A). To determine whether butein-mediated upregulation of $\mathrm{I} \kappa \mathrm{B} \alpha$ is due to transcriptional activation of I $\kappa \mathrm{B} \alpha$, we examined the expression of I $\mathrm{B} \alpha$ mRNA in cells treated with butein by RT-PCR. As shown in Fig. 6B, butein treatment had no influence on $\mathrm{I} \kappa \mathrm{B} \alpha \mathrm{mRNA}$, suggesting that butein induces the inhibition of degradation of I $\kappa \mathrm{B} \alpha$ protein. Next, we measured total and phospho-protein levels of IKK $\alpha$ and IKK $\beta$ to evaluate the possible inhibitory mechanism of butein on I $\kappa \mathrm{B} \alpha$ protein phosphorylation. Immunoblot analysis demonstrated butein dose-dependent suppression of phosphoprotein levels of IKK $\alpha$ and IKK $\beta$ in MT- 4 and HUT-102 cells. Total protein levels of both IKK $\alpha$ and IKK $\beta$ were reduced in HUT-102 cells, while total protein level of IKK $\beta$ alone was reduced in MT-4 cells (Fig. 6A). Thus, the effects of butein seem to slightly differ dependent on cell lines.

$\mathrm{NF}-\kappa \mathrm{B}$ is a complex of proteins, in which various combinations of $N F-\kappa B$ proteins constitute active NF- $\kappa B$ heterodimers that bind to specific DNA sequences. Thus, to show that 
A

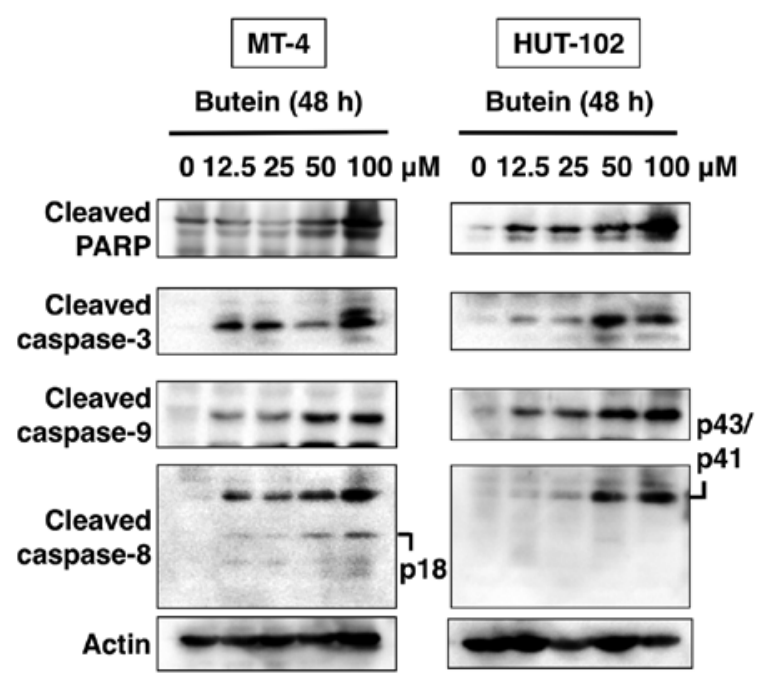

B

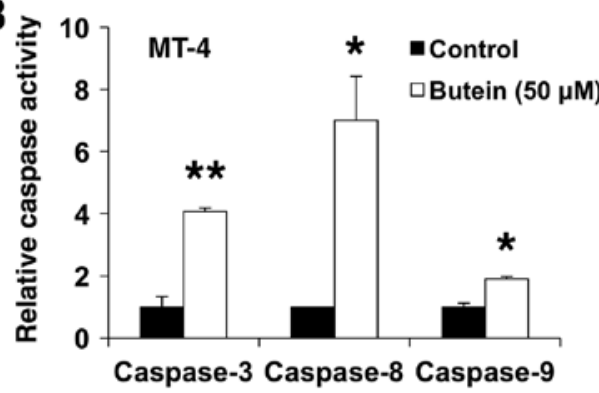

C

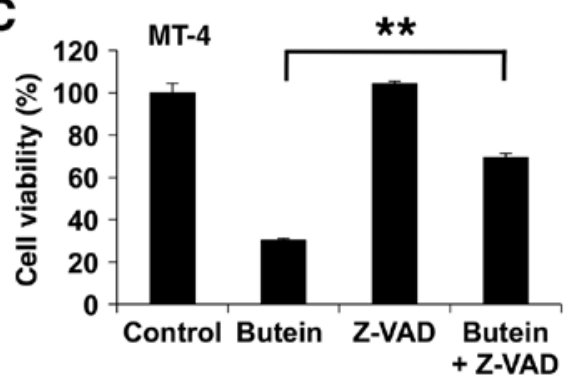

Figure 4. Effects of butein on activation of caspases. (A) Effects of butein on protein expression of cleaved caspase-3, -8, -9 and PARP. MT-4 and HUT-102 cells were incubated with different concentrations of butein $(12.5-100 \mu \mathrm{M})$ for $48 \mathrm{~h}$ and then harvested. Total cell lysates were prepared, and protein was subjected to SDS-PAGE followed by immunoblot analysis and chemiluminescence detection. Equal loading of protein was confirmed by stripping the immunoblot and reprobing it for actin. (B) Caspase-3, -8 and -9 activities were determined using relevant caspase colorimetric assay kits. MT-4 cells were treated with $50 \mu \mathrm{M}$ of butein for $48 \mathrm{~h}$ and then lysed for protein extraction. Quantitative results of caspase-3, -8 and -9 activity levels, which were expressed as multiples of induction beyond each respective control. Data are mean $\pm \mathrm{SD}$ values of triplicate cultures. ${ }^{*} \mathrm{P}<0.05$ and ${ }^{* *} \mathrm{P}<0.01$, vs. vehicle-treated control. (C) Effect of pan-caspase inhibitor on butein-induced cell death. MT-4 cells were incubated with $20 \mu \mathrm{M}$ of Z-VAD-FMK for $1 \mathrm{~h}$, followed by addition of butein ( $25 \mu \mathrm{M}$; $48 \mathrm{~h}$ ). Cell viability was determined by the WST- 8 assay. Data are mean \pm SD of triplicate cultures. ${ }^{* *} \mathrm{P}<0.01$ vs. butein-treated control.

A

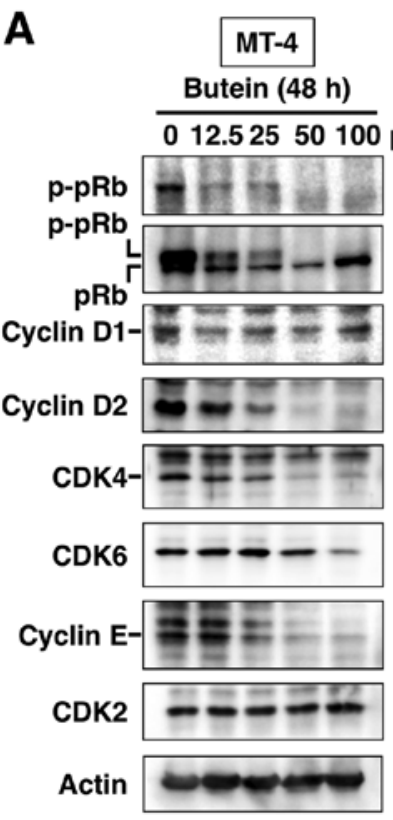

B \begin{tabular}{|l|} 
BUT-102 \\
Butein (48 h) \\
$012.52550100 \mu \mathrm{M}$
\end{tabular}
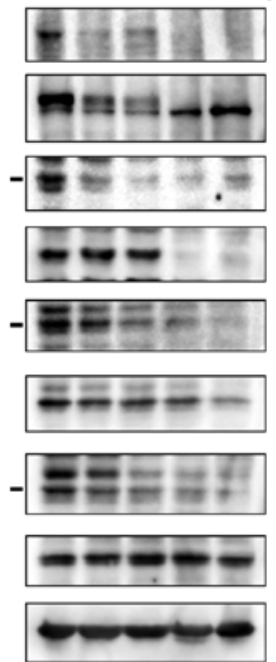

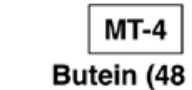

T-4 Butein (48 h)

HUT-102

$\overline{012.52550100} \mu \mathrm{M} \overline{012.52550100} \mu \mathrm{M}$

Survivin

$---\infty-$

XIAP

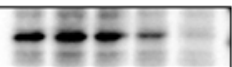

C-IAP2 $--\pi+4$

$\mathrm{Bcl}-2$ - -

Actin
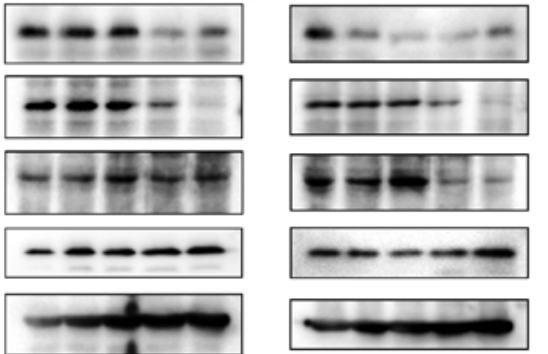

Figure 5. Effect of butein on the expression of various cell cycle regulatory proteins and anti-apoptotic proteins. (A) Effects of butein on protein expression of phosphorylated pRb, cyclins and CDKs in MT-4 and HUT-102 cells. The cells were cultured with the indicated concentrations of butein for $48 \mathrm{~h}$. (B) Effects of butein on the expression of various anti-apoptotic proteins in MT-4 and HUT-102 cells. The cells were treated with butein (12.5-100 $\mu \mathrm{M}$; $48 \mathrm{~h})$ and then harvested. Total cell lysates were prepared, and protein was subjected to SDS-PAGE followed by immunoblot analysis and chemiluminescence detection. Actin was used as the internal control.

the band visualized by EMSA in HTLV-1-infected T-cell lines was indeed NF- $\mathrm{KB}$, nuclear extracts from MT-4 and HUT-102 cells were incubated with antibodies to the NF- $\kappa B$ subunits and analyzed by EMSA. The results showed shifts of the bands to higher molecular masses (Fig. 6C), suggesting that the activated complex consisted of p50, RelA and RelB. The addition of excess unlabeled NF- $\mathrm{KB}$ caused complete disappearance of the band, whereas the addition of AP-1 oligonucleotide had no effect on the DNA binding. We also investigated whether butein could inhibit constitutive NF- $\mathrm{KB}$ 


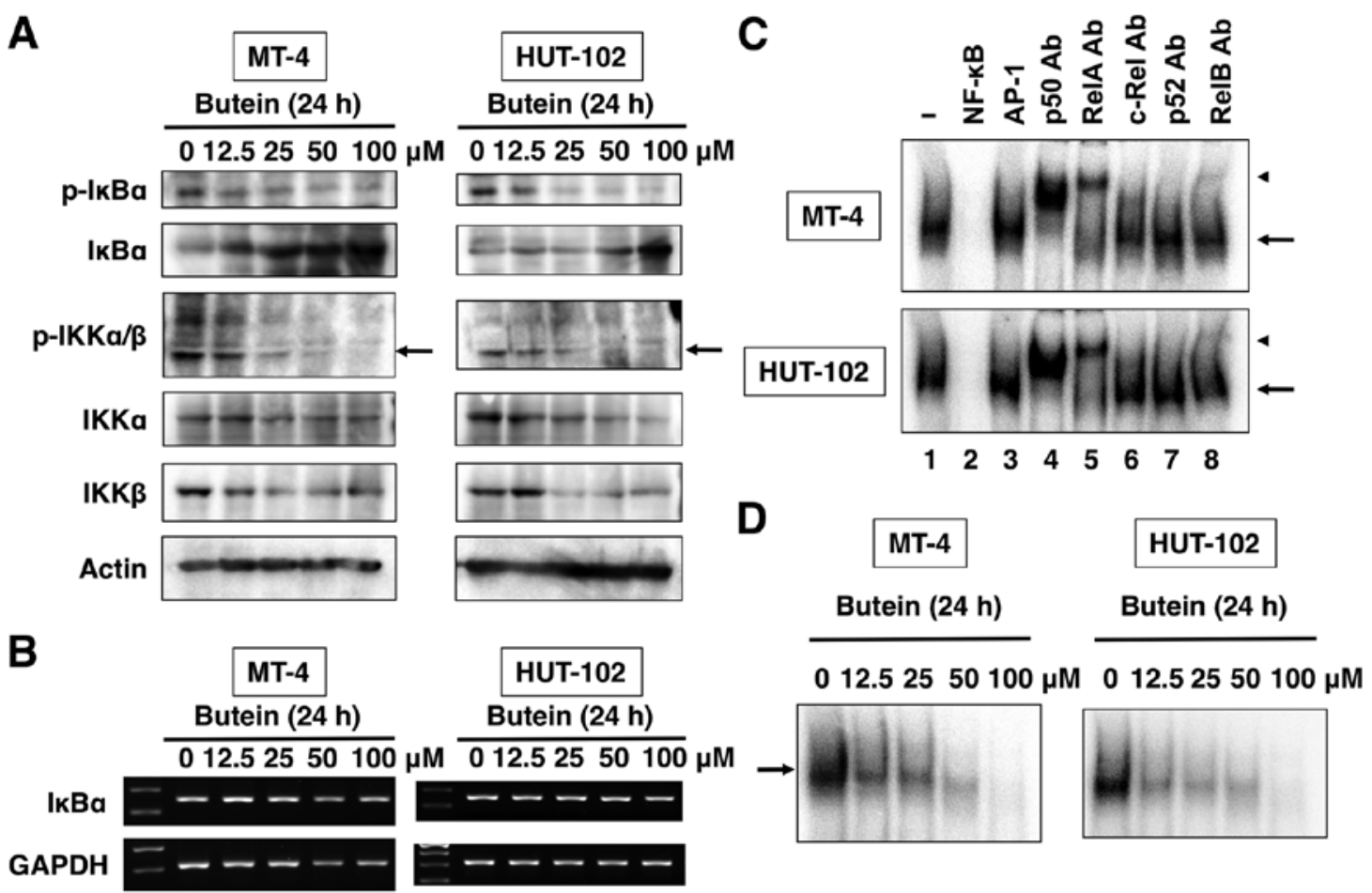

Figure 6. Butein inhibits constitutively active NF-кB in HTLV-1-infected T-cell lines. (A) Butein inhibits total and phospho-protein levels of IKK $\alpha / \beta$ and suppresses phosphorylation of IкB $\alpha$. MT-4 and HUT-102 cells were treated with the indicated concentrations of butein for $24 \mathrm{~h}$, after which the cell extracts were prepared, and protein was resolved on SDS-PAGE. (B) Effects of butein on I $\mathrm{kB} \alpha \mathrm{mRNA}$ expression in HTLV-1-infected T-cell lines. MT-4 and HUT-102 cells were cultured with the indicated concentrations of butein for $6 \mathrm{~h}$, and total RNA extracted from cells was subjected to RT-PCR. GAPDH as internal control.

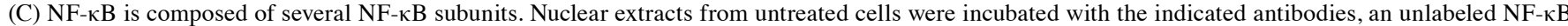
or AP-1 oligo probe. They were then assayed for NF- $\mathrm{kB}$ activation by EMSA. Ab, antibody. Arrow and arrowhead show a specific complex and a supershifted band, respectively. (D) MT-4 and HUT-102 cells were treated with the indicated concentrations of butein for $24 \mathrm{~h}$. The nuclear extracts were assayed for NF- $\mathrm{kB}$ activation by EMSA. Arrow shows a specific complex.

in HTLV-1-infected T-cell lines. MT-4 and HUT-102 cells were cultured in the presence of different concentrations of butein for $24 \mathrm{~h}$ and then analyzed for NF- $\mathrm{kB}$ activation. Butein dose-dependently inhibited constitutive NF- $\kappa \mathrm{B}$ activation in HTLV-1-infected T-cell lines (Fig. 6D). These results indicate that butein can suppress constitutively active $\mathrm{NF}-\kappa \mathrm{B}$ in HTLV-1-infected T cells.

Butein suppresses AP-1 activity. AP-1 is a group of dimeric transcription factor complexes composed of members of the Fos (c-Fos, FosB, Fra-1 and Fra-2) and Jun (c-Jun, JunB and JunD) families, which play central roles in the proliferation and transformation of $\mathrm{T}$ cells (6). EMSA showed supershifted band for AP-1, as detected with specific antibodies to JunB and JunD in MT-4 and HUT-102 cells (Fig. 7A). As shown in Fig. 7B, butein produced a significant and dose-dependent suppression of AP-1 activation in HTLV-1-infected T-cell lines. As shown in Fig. 7A, JunB and JunD are functional components of AP-1 transcription factor in HTLV-1-infected T-cell lines. The experiment demonstrated that butein inhibited AP-1 signaling pathway through dose-dependent suppression of JunB and JunD protein levels (Fig. 7C).

Butein inhibits Akt and HSP90 protein expression in HTLV-1infected T-cell lines. Akt is a component of an essential pathway for cell survival and growth during development and carcinogenesis. It regulates cell survival by directly targeting XIAP and by indirectly modulating survivin levels $(19,20)$.
Akt also regulates cell cycle and proliferation by indirectly modulating the levels of cyclin D1, cyclin D2 and cyclin E (21). Since butein decreased the levels of XIAP, survivin, cyclin D1, cyclin D2 and cyclin E in the treated cells, we determined its effect on Akt protein. Butein at 50-100 $\mu \mathrm{M}$ for MT-4 and 12.5-100 $\mu \mathrm{M}$ for HUT-102 cells, caused a dose-dependent inhibition of Akt protein expression. Treatment of MT-4 cells with butein at 50-100 $\mu \mathrm{M}$ and HUT-102 cells with butein at 12.5-100 $\mu \mathrm{M}$ caused a dose-dependent inhibition in Akt phosphorylation at Thr308. Butein at 12.5-100 $\mu \mathrm{M}$ for MT-4 and 25-100 $\mu \mathrm{M}$ for HUT-102 cells, also inhibited the phosphorylation of Akt at Ser473 (Fig. 8). RelA is phosphorylated at Ser536 by Akt and such phosphorylation enhances RelA transactivation potential (22). Butein also caused inhibition of RelA phosphorylation (Fig. 8). The molecular chaperone HSP90 is involved in the stabilization and conformational maturation of many signaling proteins that are deregulated in cancers. HSP90 client proteins include signaling proteins (IKKs and Akt) and cell cycle regulators (CDKs) (23). Therefore, we investigated the effect of butein on the expression of HSP90. As shown in Fig. 8, butein reduced HSP90 protein levels, but increased HSP70 levels.

Butein suppresses growth of HTLV-1-infected T-cell line in SCID mice. Butein significantly inhibited tumor growth in SCID mice inoculated with HTLV-1-infected HUT-102 cells (Fig. 9A, left panels). In the control group, the average tumor volume of $1,545 \mathrm{~mm}^{3}$ was reached in 28 days after 
A

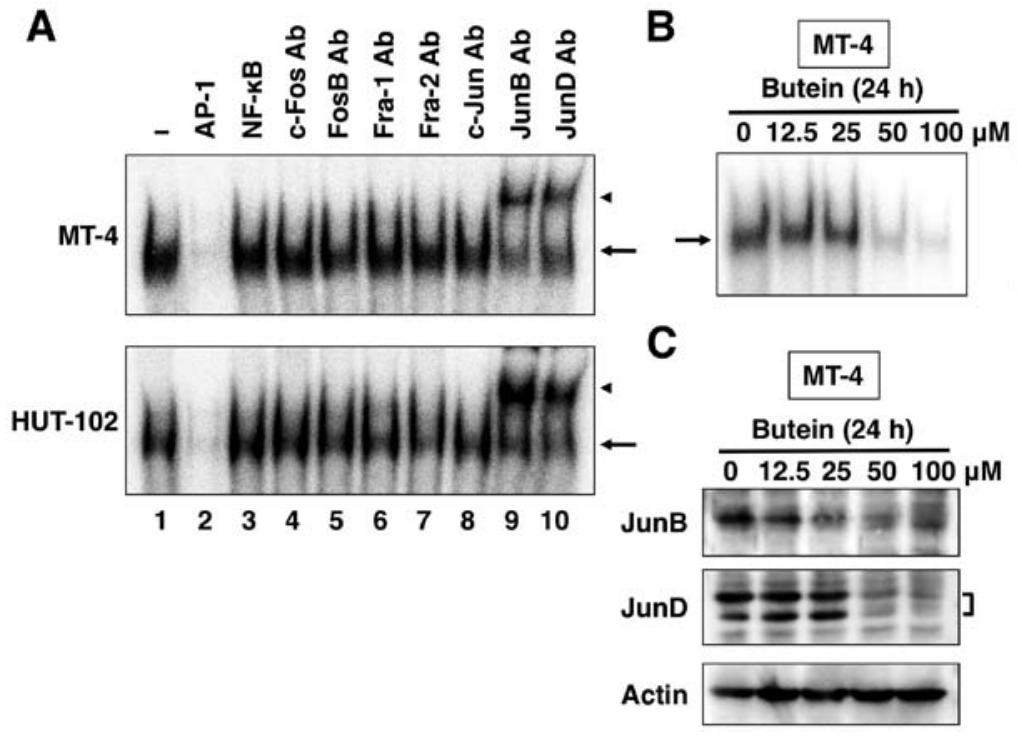

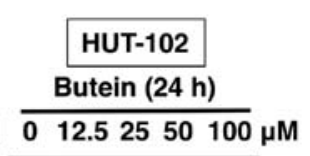

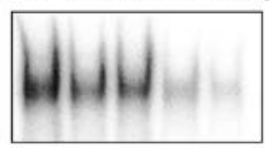

HUT-102

Butein (24 h)

$012.52550100 \mu \mathrm{M}$

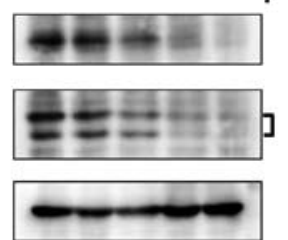

Figure 7. Butein inhibits constitutively active AP-1 in HTLV-1-infected T-cell lines. (A) AP-1 is composed of JunB and JunD subunits. Nuclear extracts from untreated cells were incubated with the indicated antibodies, unlabeled AP-1 or NF- $\kappa$ B oligo probe. They were then assayed for AP-1 activation by EMSA. Ab, antibody. Arrow and arrowhead show a specific complex and a supershifted band, respectively. (B) MT-4 and HUT-102 cells were treated with the indicated concentrations of butein for $24 \mathrm{~h}$. The nuclear extracts were assayed for AP-1 activation by EMSA. Arrow shows a specific complex. (C) Butein downregulates the expression of JunB and JunD proteins. Cells were treated with the indicated concentrations of butein for $24 \mathrm{~h}$. The total protein extracts were prepared for immunoblot analysis. Actin was used as the loading control.

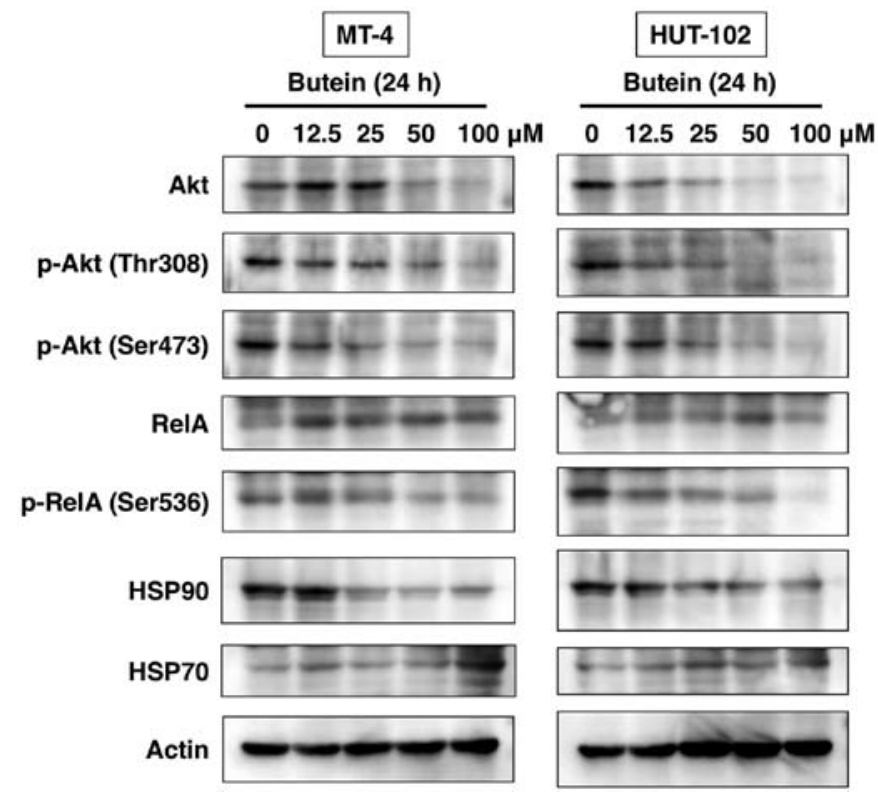

Figure 8. Effects of butein on Akt signaling pathway and HSP proteins. Cells were treated with the indicated concentrations of butein for $24 \mathrm{~h}$. Cell lysates were separated by SDS-PAGE and protein levels of phosphorylated and total Akt and RelA, and HSPs were analyzed with immunoblotting. Actin was used as the internal control.

HUT-102 cell inoculation (Fig. 9B, left panel). At the same time point, the average tumor volume in the butein-treated group was $727 \mathrm{~mm}^{3}$. Tumor tissues were removed, photographed (Fig. 9A, right panel), and weighed. The mean tumor weight of butein-treated mice was significantly lower than that of vehicle-treated mice (Fig. 9B, middle panel). In addition, the body weight of mice remained stable with no significant differences between the two groups (Fig. 9B, right panel). At post-inoculation day 28, quantitative ELISA used to determine the circulating levels of surrogate tumor markers sCD25 (24) and sCD30 (25) secreted by HUT-102 tumor xenografts showed $42 \%$ and $59 \%$ decrease in their levels, respectively, in butein-treated mice, compared with the control group (Fig. 9C). Considered together, our results showed that treatment with butein resulted in significant decreases in serum sCD25 and sCD30 of SCID mice.

Finally, H\&E and TUNEL staining assays were performed to assess whether the inhibitory effect on tumor growth induced by butein was due to an increase in apoptotic cell death. H\&E staining showed a significant increase in apoptotic tumor cells in butein-treated mice, compared with the control group, which were characterized by cytoplasmic condensation, chromatin hyperchromatism and condensation, and nuclear fragmentation. TUNEL assays confirmed these findings and demonstrated increased number of TUNEL-positive tumor cells in butein-treated mice (Fig. 9D).

\section{Discussion}

ATLL is classified into four clinical subtypes based on the clinical manifestations: acute, lymphoma, chronic and smoldering (26). Acute, lymphoma and unfavorable chronic types are considered the aggressive forms of ATLL, while favorable chronic and smoldering types are indolent ATLL (26). Various dietary and lifestyle factors may be involved in the development and progression of ATLL. Aggressive ATLL carries poor prognosis, with only $24 \%$ for 3 -year overall survival rate in patients on standard combination chemotherapy (27). Therefore, there is a great need for novel therapeutic approaches for ATLL. Chemotherapeutic agents are usually highly toxic to normal tissues. To reduce the number of HTLV-1-infected T cells, natural products are suitable alternatives since they have minimal side-effects compared to synthetic drugs. 

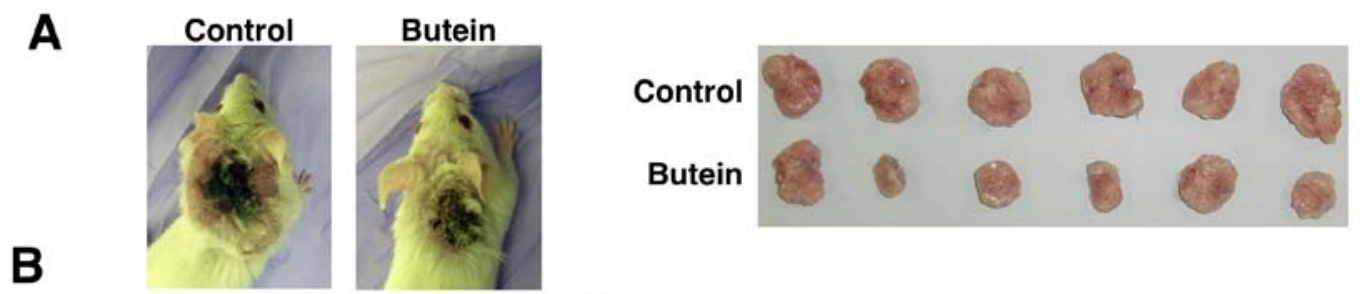
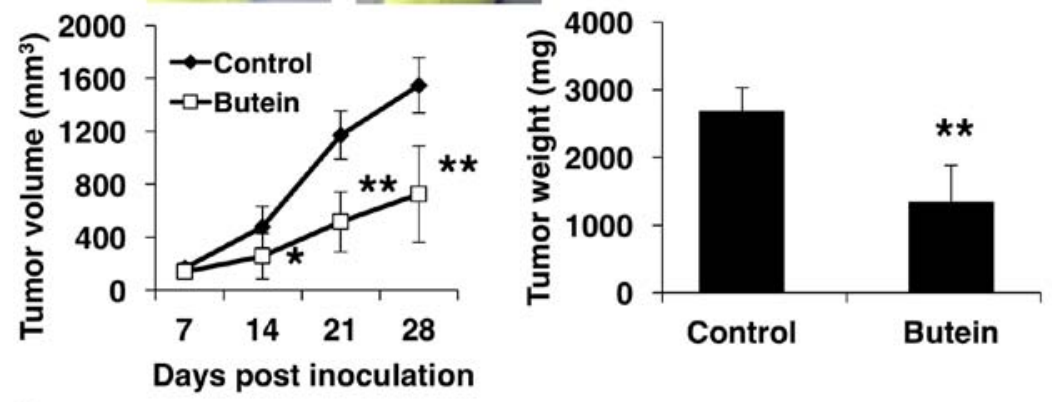

D

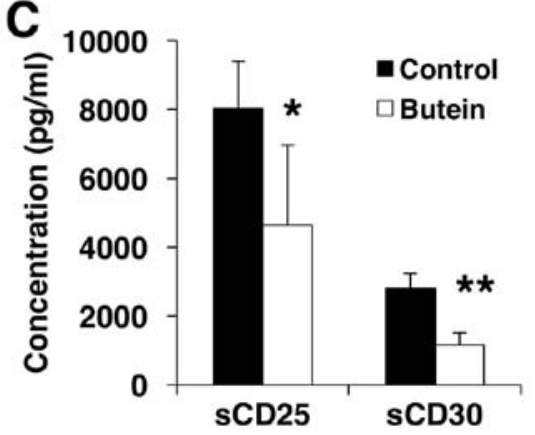

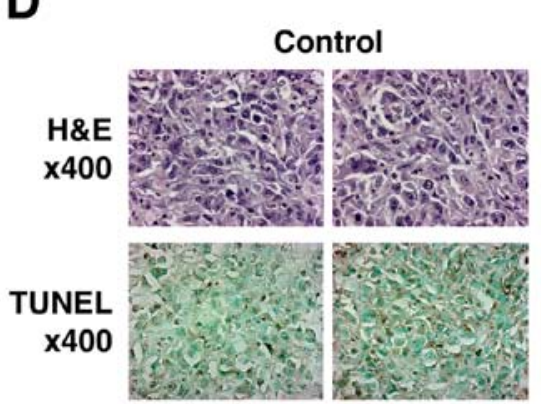
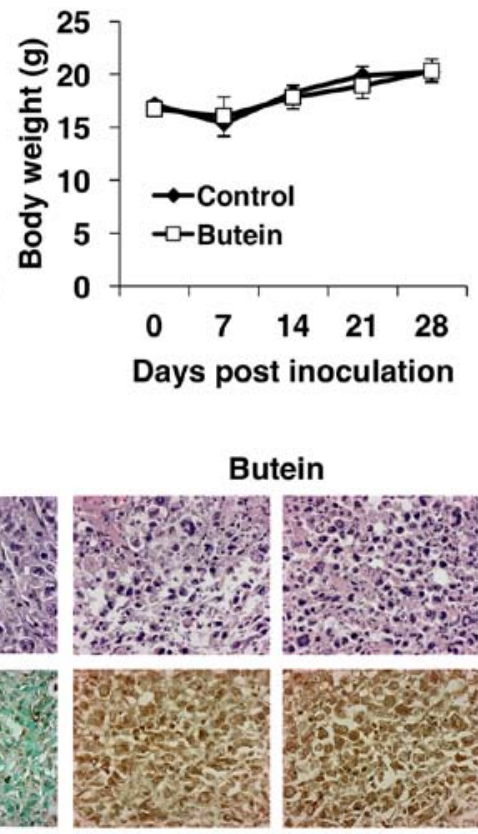

Figure 9. Antitumor effects of butein in HUT-102 tumor-bearing SCID mice. (A) HUT-102 cells were transplanted subcutaneously into the postauricular region of SCID mice $(n=6)$. Mice were treated with butein $(0.7 \mathrm{mg} / \mathrm{kg})$ or vehicle three times a week (left panels). Visible HUT-102 xenograft tumors were harvested before sacrifice (right panel). (B) Serial changes in tumor volume (left panel) and body weight of mice (right panel) during the experiment. Weight of tumor tissues from the butein and control groups (middle panel). Data are mean $\pm \mathrm{SD}$ values. ${ }^{*} \mathrm{P}<0.05$ and ${ }^{* *} \mathrm{P}<0.01$, vs. vehicle-treated control. (C) Mean $\pm \mathrm{SD}$ values of serum concentrations of sCD25 and sCD30 in mice. ${ }^{*} \mathrm{P}<0.05$ and ${ }^{* *} \mathrm{P}<0.01$, vs. vehicle-treated control. (D) Cell apoptosis in tumor tissues determined by H\&E and TUNEL staining. Magnification, $x 400$.

In this study, we showed that butein decreased cell viability of HTLV-1-infected T-cell lines. The ability of the cells to divide is regulated by two classes of molecules, CDKs, a family of serine/threonine kinases and their binding partners, cyclins. The progress of the cells division process occurs through the interaction of various cyclins with their respective CDK subunits (28). Quiescent cells enter the cell cycle after mitogenic stimulation and upregulation of cyclins $\mathrm{D}$ and $\mathrm{E}$ during the $\mathrm{G}_{1}$ phase of the cell cycle (29). Cyclin D is associated with CDK4 and CDK6 (30), while cyclin E is associated with CDK2 (31). Thus, cyclins and CDKs play important roles in DNA synthesis and cell division. In contrast, $\mathrm{pRb}$ controls cell cycle progression at the $G_{1}$ to $S$ transition in response to certain signals for growth inhibition (32). pRb is phosphorylated by catalytic subunits of CDK4/CDK6 and CDK2 complexed with specific regulatory subunits of cyclins $\mathrm{D}$ and E, respectively. Treatment of HTLV-1-infected T-cell lines with butein reduced the expression levels of cyclin D1, D2, E, CDK4, CDK6 and phospho-pRb. Based on these findings, it is highly possible that butein causes $\mathrm{G}_{1}$ arrest by blocking cyclin D-CDK4/6- and cyclin E-CDK2-mediated pRb phosphorylation, which is crucial to the progression of the cell cycle at the $\mathrm{G}_{1}$ to $\mathrm{S}$ transition.

The process of apoptosis is controlled by various interrelated pathways, which ensure that caspases, the proteolytic initiators, and executioners of apoptosis, are triggered only in cells requiring termination. We have shown in the present study the activation of caspase- $3,-8$ and -9 during the application of butein and that the addition of a general caspase inhibitor partially decreased butein-mediated cell death. These data provide evidence that butein-induced apoptosis was at least in part caspase-dependent in HTLV-1-infected T-cell lines. Butein also downregulated the protein expression of survivin, XIAP and c-IAP2, which are possible upstream factors of caspase proteins.

$\mathrm{NF}-\mathrm{\kappa B}$ can modulate the transcriptional activation of genes associated with cell proliferation, metastasis, tumor promotion and suppression of apoptosis $(33,34)$. Hence, agents capable of suppressing NF- $\mathrm{\kappa B}$ activation are therapeutically promising in inhibiting carcinogenesis. Our results suggest that the effects of butein on NF- $\mathrm{KB}$ were mediated through inhibition of phosphorylation and the associated subsequent proteolysis of $I \kappa \mathrm{B} \alpha$ since butein blocked phosphorylation and degradation of I $\mathrm{K} \mathrm{B} \alpha$. Furthermore, butein inhibited total and phospho-protein levels of IKK $\alpha$ and IKK $\beta$, and phosphorylation of RelA. Treatment of HTLV-1-infected T-cell lines with butein further inhibited NF- $\mathrm{kB}$-regulated gene products, survivin, XIAP, c-IAP2, cyclin D1, cyclin D2, CDK4 and CDK6.

Akt occupies a key regulatory node in the phosphoinositide 3-kinase pathway, below which the pathway branches 
significantly to influence a wide range of cellular processes that promote cell cycle progression, cell growth and resistance to apoptosis by modulating the levels of survivin, XIAP, cyclin D1, cyclin D2 and cyclin E (19-21). Our results demonstrated that butein decreased total and phospho-protein levels of Akt in HTLV-1-infected T-cells. Akt is known to phosphorylate RelA at Ser536 through an IKK $\alpha$ - or IKK $\beta$-dependent mechanism (35). Butein may inhibit phosphorylation of RelA through inactivation of Akt and IKKs. In addition, AP-1 regulates the expression and function of various cell cycle regulators, such as cyclin D1 and cyclin E (36). JunB is also controlled by NF- $\mathrm{BB}$ (37). Thus, NF-kB and AP-1 can also collaborate in ATLL, depending on a variety of factors. Butein inhibited AP-1 signaling pathway via reduction of JunB and JunD. Considered together, these findings suggest that the effects of butein are mediated through a diverse range of molecular targets, which collectively result in inhibition of cell growth and survival.

Of note, butein profoundly inhibited HSP90 protein. Previous studies showed that HSP90 inhibitors simultaneously inactivated and destabilized several oncoproteins (e.g., IKKs, Akt and CDKs) in cancer cells $(23,38)$. On the other hand, inhibition of HSP90 alone induces upregulation of another chaperone, HSP70 (38). Our results also showed that butein increased the expression of HSP70. HSP70 is known to be anti-apoptotic, and therefore the induction of HSP70 may ultimately limit the efficacy of HSP90 inhibitors (38). Collectively, these results suggest that butein also inhibits HSP90, thereby affecting various signaling pathways involved in the regulation of cell growth and survival.

To establish the relevance of these in vitro findings to the intact animal, we implanted SCID mice with HTLV-1-infected T cell line HUT-102. Treatment with butein significantly decreased HUT-102 growth in these mice and significantly reduced serum levels of sCD25 and sCD30 without affecting body weight. The results also showed upregulation of TUNELpositive cells undergoing early apoptosis in tissues of mice treated with butein, relative to the control mice.

In conclusion, we demonstrated in the present study the effects of butein, a plant polyphenol, on the growth of HTLV-1infected T-cell lines in both in vitro and in an in vivo animal model. Although this study warrants further investigation on ATLL primary samples, the results suggest that butein is a potentially valuable chemopreventive and/or chemotherapeutic agent against ATLL.

\section{Acknowledgements}

We thank Fujisaki Cell Center, Hayashibara Biochemical Laboratories, Inc. (Okayama, Japan) for providing HUT-102. This work was supported in part by JSPS KAKENHI grant numbers, 25830085 and 25461428 , and a grant from the Mishima Kaiun Memorial Foundation.

\section{References}

1. Gonçalves DU, Proietti FA, Ribas JG, Araújo MG, Pinheiro SR, Guedes AC and Carneiro-Proietti AB: Epidemiology, treatment, and prevention of human T-cell leukemia virus type 1-associated diseases. Clin Microbiol Rev 23: 577-589, 2010.

2. Gessain A and Cassar O: Epidemiological aspects and world distribution of HTLV-1 infection. Front Microbiol 3: 388, 2012.
3. Okayama A, Stuver S, Matsuoka M, Ishizaki J, Tanaka G, Kubuki Y, Mueller N, Hsieh CC, Tachibana N and Tsubouchi H: Role of HTLV-1 proviral DNA load and clonality in the development of adult T-cell leukemia/lymphoma in asymptomatic carriers. Int J Cancer 110: 621-625, 2004.

4. Nagai M, Usuku K, Matsumoto W, Kodama D, Takenouchi N, Moritoyo T, Hashiguchi S, Ichinose M, Bangham CR, Izumo S, et al: Analysis of HTLV-I proviral load in $202 \mathrm{HAM} / \mathrm{TSP}$ patients and 243 asymptomatic HTLV-I carriers: High proviral load strongly predisposes to HAM/TSP. J Neurovirol 4: 586-593, 1998.

5. Mori N: Cell signaling modifiers for molecular targeted therapy in ATLL. Front Biosci (Landmark Ed) 14: 1479-1489, 2009.

6. Hall WW and Fujii M: Deregulation of cell-signaling pathways in HTLV-1 infection. Oncogene 24: 5965-5975, 2005.

7. Surh Y-J: Cancer chemoprevention with dietary phytochemicals. Nat Rev Cancer 3: 768-780, 2003.

8. Yadav VR, Prasad S, Sung B and Aggarwal BB: The role of chalcones in suppression of NF- $\kappa \mathrm{B}$-mediated inflammation and cancer. Int Immunopharmacol 11: 295-309, 2011.

9. Gupta SC, Kim JH, Prasad S and Aggarwal BB: Regulation of survival, proliferation, invasion, angiogenesis, and metastasis of tumor cells through modulation of inflammatory pathways by nutraceuticals. Cancer Metastasis Rev 29: 405-434, 2010.

10. Lee S-H, Choi W-C, Kim K-S, Park J-W, Lee S-H and Yoon S-W: Shrinkage of gastric cancer in an elderly patient who received Rhus verniciflua Stokes extract. J Altern Complement Med 16: 497-500, 2010.

11. Woo S-M, Choi YK, Kim AJ, Cho S-G and Ko S-G: p53 causes butein-mediated apoptosis of chronic myeloid leukemia cells Mol Med Rep 13: 1091-1096, 2016.

12. Zhang L, Yang X, Li X, Li C, Zhao L, Zhou Y and Hou H: Butein sensitizes HeLa cells to cisplatin through the AKT and ERK/p38 MAPK pathways by targeting FoxO3a. Int J Mol Med 36: 957-966, 2015.

13. Bai X, Ma Y and Zhang G: Butein suppresses cervical cancer growth through the PI3K/AKT/mTOR pathway. Oncol Rep 33: 3085-3092, 2015.

14. Mori $\mathrm{N}$ and Prager D: Transactivation of the interleukin-1alpha promoter by human T-cell leukemia virus type I and type II Tax proteins. Blood 87: 3410-3417, 1996.

15. Zhang C, Ao Z, Seth A and Schlossman SF: A mitochondrial membrane protein defined by a novel monoclonal antibody is preferentially detected in apoptotic cells. J Immunol 157: 3980-3987, 1996 .

16. Khan N, Afaq F and Mukhtar H: Apoptosis by dietary factors: The suicide solution for delaying cancer growth. Carcinogenesis 28: 233-239, 2007.

17. Lim S and Kaldis P: Cdks, cyclins and CKIs: Roles beyond cell cycle regulation. Development 140: 3079-3093, 2013.

18. Hayden MS and Ghosh S: Shared principles in NF-kappaB signaling. Cell 132: 344-362, 2008.

19. Dan HC, Sun M, Kaneko S, Feldman RI, Nicosia SV, Wang H-G, Tsang BK and Cheng JQ: Akt phosphorylation and stabilization of X-linked inhibitor of apoptosis protein (XIAP). J Biol Chem 279: 5405-5412, 2004

20. Vaira V, Lee CW, Goel HL, Bosari S, Languino LR and Altieri DC: Regulation of survivin expression by IGF-1/mTOR signaling. Oncogene 26: 2678-2684, 2007.

21. Zhang X, Tang N, Hadden TJ and Rishi AK: Akt, FoxO and regulation of apoptosis. Biochim Biophys Acta 1813: 1978-1986, 2011.

22. Sizemore N, Leung S and Stark GR: Activation of phosphatidylinositol 3-kinase in response to interleukin-1 leads to phosphorylation and activation of the NF-kappaB p65/RelA subunit. Mol Cell Biol 19: 4798-4805, 1999.

23. Kamal A, Boehm MF and Burrows FJ: Therapeutic and diagnostic implications of Hsp90 activation. Trends Mol Med 10: 283-290, 2004.

24. Kamihira S, Atogami S, Sohda H, Momita S, Yamada Y and Tomonaga M: Significance of soluble interleukin-2 receptor levels for evaluation of the progression of adult T-cell leukemia. Cancer 73: 2753-2758, 1994.

25. Nishioka C, Takemoto S, Kataoka S, Yamanaka S, Moriki T, Shoda M, Watanabe T and Taguchi H: Serum level of soluble CD30 correlates with the aggressiveness of adult T-cell leukemia/ lymphoma. Cancer Sci 96: 810-815, 2005.

26. Shimoyama M: Diagnostic criteria and classification of clinical subtypes of adult T-cell leukaemia-lymphoma. A report from the Lymphoma Study Group (1984-87). Br J Haematol 79: 428-437, 1991. 
27. Tsukasaki K, Utsunomiya A, Fukuda H, Shibata T, Fukushima T, Takatsuka Y, Ikeda S, Masuda M, Nagoshi H, Ueda R, et al; Japan Clinical Oncology Group Study JCOG9801: VCAP-AMP-VECP compared with biweekly CHOP for adult T-cell leukemialymphoma: Japan Clinical Oncology Group Study JCOG9801. J Clin Oncol 25: 5458-5464, 2007.

28. Morgan DO: Cyclin-dependent kinases: Engines, clocks, and microprocessors. Annu Rev Cell Dev Biol 13: 261-291, 1997.

29. Lew DJ, Dulić V and Reed SI: Isolation of three novel human cyclins by rescue of G1 cyclin (Cln) function in yeast. Cell 66: 1197-1206, 1991.

30. Bates S, Bonetta L, MacAllan D, Parry D, Holder A, Dickson C and Peters G: CDK6 (PLSTIRE) and CDK4 (PSK-J3) are a distinct subset of the cyclin-dependent kinases that associate with cyclin D1. Oncogene 9: 71-79, 1994.

31. Koff A, Giordano A, Desai D, Yamashita K, Harper JW, Elledge S, Nishimoto T, Morgan DO, Franza BR and Roberts JM: Formation and activation of a cyclin E-cdk 2 complex during the G1 phase of the human cell cycle. Science 257: 1689-1694, 1992.
32. Weinberg RA: The retinoblastoma protein and cell cycle control. Cell 81: 323-330, 1995.

33. Ben-Neriah Y and Karin M: Inflammation meets cancer, with $\mathrm{NF}-\kappa \mathrm{B}$ as the matchmaker. Nat Immunol 12: 715-723, 2011.

34. Jost PJ and Ruland J: Aberrant NF-kappaB signaling in lymphoma: Mechanisms, consequences, and therapeutic implications. Blood 109: 2700-2707, 2007.

35. Viatour P, Merville MP, Bours V and Chariot A: Phosphorylation of NF-kappaB and IkappaB proteins: Implications in cancer and inflammation. Trends Biochem Sci 30: 43-52, 2005.

36. Hess J, Angel P and Schorpp-Kistner M: AP-1 subunits: Quarrel and harmony among siblings. J Cell Sci 117: 5965-5973, 2004.

37. Pahl HL: Activators and target genes of Rel/NF-kappaB transcription factors. Oncogene 18: 6853-6866, 1999.

38. Drysdale MJ, Brough PA, Massey A, Jensen MR and Schoepfer J: Targeting Hsp90 for the treatment of cancer. Curr Opin Drug Discov Devel 9: 483-495, 2006. 